\title{
Open Design: Contributions, Solutions, Processes and Projects
}

\author{
James Tooze, ${ }^{1}$ Sharon Baurley, ${ }^{1}$ Robert \\ Phillips, ${ }^{1}$ Paul Smith, ${ }^{2}$ Edwin Foote ${ }^{1}$ and \\ Sarah Silve ${ }^{3}$ \\ 'Design Products, Royal College of Art, UK \\ ${ }^{2}$ The Glasgow School of Art, UK \\ ${ }^{3}$ School of Engineering and Design, Brunel \\ University, UK
}
ABSTRACT Open design is a catchall term for various on- and offline design and making activities. It can be used to describe a type of design process that allows for (is open to) the participation of anybody (novice or professional) in the collaborative development of something. As well as this, it can mean the distribution and unrestricted use of design blueprints and documentation for the use by others.
In this paper, the authors highlight various aspects of open and collaborative design and argue for the use of new terms that address what is open and when. A range 


\section{of design projects and online platforms that have open attributes are then explored, whereby these terms are applied. In terms of design, the focus is specifically on the design of physical things rather than graphical, software or system design.}

KEYWORDS: open design, co-creation, co-design, definitions

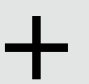

Introduction

This paper will first explore the inherent difficulty in using the term open design to describe both the free distribution of design data and free access to participation in a design project. Definitions of open design are given, as are similar concepts of open innovation (Chesbrough, 2006), open source innovation (Raasch et al, 2009) and co-design (Sanders and Stappers, 2008) in order to draw parallels and highlight differences. The paper will set out a case for the use of clear definitions to determine the characteristics of open and collaborative design. For those unfamiliar with open design as a phenomenon, a number of example design projects and online platforms are explored that can be seen to be, or explicitly claim to be, open. The examples are loosely grouped into sections that associate them through shared attributes to illustrate the scope of this phenomenon. Following each section, a short summary is given using the definitions outlined previously in the paper, in order to demonstrate how these can be applied.

\section{Defining Design}

Open design as a phenomenon, as Bas van Abel explains 'covers an extensive area and its contours are not yet clearly defined, making it difficult for designers to come to grips with' (van Abel, 2011). It is a sufficiently ambiguous and blurry term that Massimo Menichinelli (2011), based at Aalto Media Factory in collaboration with The Open Design Working Group, is seeking to define a definition of open design that will bring clarity to what it covers and set conditions for its application (Menichinelli, 2013).

Open design, much like the word design itself, is an extremely broad and often ambiguous term; as design writer John Heskett points out 'design is when designers design a design to produce a design' (Heskett, 2005). He explains how there are four differing uses of the word design:

The first usage is as a noun, connoting the field of design as a whole in a very general manner, as in the phrase: 'Design is important to national economic competitiveness.' The second usage is as a verb, meaning the action or thought involved in the act of designing. The third also is a noun; this time connoting a plan or intention. Finally, the fourth usage again is 
a noun, this time meaning the finished product. All the usages have very different meanings, yet even people professionally involved in design continually slip between them, seamlessly moving from one meaning to another without distinction. (Heskett, 2005)

For this paper we will use Heskett's third usage of design 'connoting a plan or intention' which covers CAD (Computer Aided Design) files, plans, blueprints documentation and instructions, to identify something as being a 'design contribution' or as part of a 'design solution'. When referring to design as a process (designing), everything that goes into a design project will be considered a 'design contribution' and the resulting final design will be considered a 'design solution'.

\section{Openness}

The sharing of knowledge, and its more practical incarnation, knowhow, is nothing new, neither is working together to make things to solve problems. Collaboration is an inherent sociocultural attribute of being human; teaching, learning and sharing form part of the social glue that binds communities, as well as being the cornerstone of human technological development. What is being seen in the phenomenon of openness on the internet is merely a continuum of a dialogue that spans human history. The significant factor today is the mechanisms and opportunity afforded by Web 2.0 alongside other digital technologies to publically share information. There are numerous examples online where things are open for others to access; collectively this is the notion of "open everything [which] has turned into a megatrend' that can be labelled the Rise of Open-X (van Abel, 2011), where $X$ stands for almost anything. Notable examples are open source software (Moody, 2002), open innovation (Chesbrough, 2003), open encyclopaedias (Wales, 2005), open journalism (Muthukumaraswamy, 2010), open production of film (Richter and Cassarino, 2008) and, the focus of this paper, open design.

Many descriptions regarding openness focus on setting the rules by which a work can be judged to be open. In setting the rules for defining any work as open the Open Knowledge Foundation states that 'a work is open if its manner of distribution satisfies [certain] conditions' and these can be summarized as:

Access or 'social' openness - where not only are you allowed to get the work but you can obtain it, in a convenient and modifiable form (Open Knowledge Foundation, 2013).

Redistribution - no restriction from selling or giving away the work either on its own or as part of a package made from works from many different sources and no royalty or other fee for such sale or distribution.

Reuse - the work and any licence must allow for modifications and derivative works. 
Absence of Technological Restriction - the work must be provided in such a form that there are no technological obstacles that limit access, redistribution or reuse.

The other seven conditions are; attribution, integrity, no discrimination against persons or groups, no discrimination against fields of endeavour, distribution of licence, licence must not be specific to a package, licence must not restrict the distribution of other works. These broadly can be summarized as: no restrictions should exist that limit who and how a work is used, and if a licence for the work exists it should not impinge on the other conditions that define a work as open. Many of these conditions are reworking of the open source definition (OSD) (Open Source Initiative, 2012).

Smith talks of open design in terms of a work of design, in line with the open description, but using a single statement that sets out the conditions of an open design (Smith, 2008). In this statement, design is described as being open when 'designs and instructions to create real, physical objects are freely shared'. The use of the term 'freely' could be interpreted as both free of cost and free from boundaries. In his open design manifesto, Ronan Kadushin states that open design 'is CAD (Computer Aided Design) information published online under a Creative Commons license to be downloaded, produced, copied and modified' (Kadushin, 2012).

In their discussion on the open design of manufacturing equipment, Vallance et al define open design as:

[enabling] collaborative efforts by providing incentives and methods for freely sharing information. Design documentation (e.g., CAD data, Finite Element Analyses, spreadsheets, simulations) and performance data (e.g., reliability, precision, accuracy, yields) are freely shared. Furthermore, the documentation can be freely modified, and artefacts produced using original or modified documentation can be distributed. If the modified design is distributed or artefacts are sold for profit, then design documentation must be publicly disclosed. (Vallance et al, 2001)

Michel Avital, writing in Open Design Now is less specific regarding collaborative efforts, the use of CAD or the need for the design to be of physical things, stating that open in design can be understood to mean allowing for access to information in relation to a design, making it 'accessible to view, modify and use' (Avital, 2011). This broad term covers any design activity where information to reproduce and derive is freely available in an attempt to encourage or facilitate collaboration. The condition that makes the design open is the public disclosure of information. This definition suggests an ongoing process of derivation and development of a design from 
a single start point, much like the open source software model of development.

\section{Collaborative Design}

As previously stated openness in the design process can be viewed as co-design or open innovation, where both allow for the participation of others in a design process. Sanders and Stappers, place co-design as 'a specific instance of co-creation'; where co-creation refers 'to any act of collective creativity, i.e., creativity that is shared by two or more people' and 'co-design as collective creativity as it is applied across the whole span of a design process' using the term 'to refer to the creativity of designers and people not trained in design working together in the design development process' (Sanders and Stappers, 2008). Co-creation can be seen in the concept of Open Innovation, which Chesbrough describes as a:

paradigm [that] can be understood as the antithesis of the traditional vertical integration model where internal research and development activities lead to internally developed products that are then distributed by the firm [...] Open Innovation [...] assumes that firms can and should use external ideas as well as internal ideas, and internal and external paths to market, as they look to advance their technology. (Chesbrough, 2006)

In combining the opening up of the design development process to others and making the work contributed and ultimately designed available openly, there is a definition that can be seen as an open design process. Raasch et al devised a definition of a type of design referred to as 'open source innovation' (Raasch et al, 2009). In their work, 'open source innovation (OSI) is characterized by the free revealing of information on a new design with the intention of collaborative development of a single design or a limited number of related designs for market or non-market exploitation'.

In both Chesbrough's definition of co-design and in Raasch et al's notion of open source innovation, there is collaborative effort towards a commonly sought solution. In the examples given later in the paper, this type of collaborative process is evident; however, there are also examples of ad hoc collaborative design where there are multiple outcomes and each design solution can be a starting point for another's project.

\section{Terms of Open Design}

In order to speak and write about open design with clarity, this paper proposes short definitions of collaborative design based on the explanations given previously in the paper as well proposing new terms pertaining to openness and design. In the following half of the paper, these terms will be used at the end of each section to summarize the examples and so illustrate their use. 


\section{Existing terms}

- Co-creation: the generation of anything by more than one person.

- Co-design: the design of something by more than one person.

- Open innovation: being open to and seeking out contributions of others outside of an organization for the purposes of bringing in new ideas.

- Open source innovation: the open sharing of design information or knowledge by an organization with collaborators as part of open innovation.

\section{Open design terms}

- Open design solution: a set of plans and instructions that enable others to make use of the design information in making or modifying the 'design solution' without restriction. A design solution is something that can be acted on directly and in the context of physical things, be made.

- Open design contribution: any contribution, in any format, to a design process that is made available for use by others without restriction.

- Open design process: the development of a design solution or solutions that are created by the input of open design contributions and results in an open design solution or solutions.

- Open designing: engaging in the design of anything by an open design process.

- Open design project: any project that follows an open design process.

\section{Visualizing Openness in Design}

In order to illustrate the open components of a design process and therefore describe it, it is useful to visualize the various parts and possible variations. Figure 1 shows simplified models of how both open and non-open design solutions can be generated by open and non-open contributions. Contributions are denoted as segments, where solutions are whole circles, and arrows indicate the direction of time. The grey circles highlight where all contributions are published openly in the development of an open solution.

\section{Designing Open Designs}

The open publication of designs, in the form of plans and instructions, of course is not a new thing. In 1971, Italian industrial designer Enzo Mari began a project that rebelled against what he saw as the shallow and status-driven product design being created by his contemporaries for mass manufacture. Autoprogettazione, which roughly translates as 'self-design', is a set of instructions for 19 pieces of self-made furniture and was initially exhibited in 1974 (Mari, 2002). Mari offered the plans for his wooden furniture to anyone who sent him a self-addressed envelope. In effect they were free except for the means of delivery, which can be seen to be comparable to 


\section{Variations of open \& non open design}
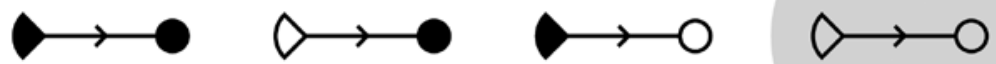

\section{Variations of collaborative open \& non open design}
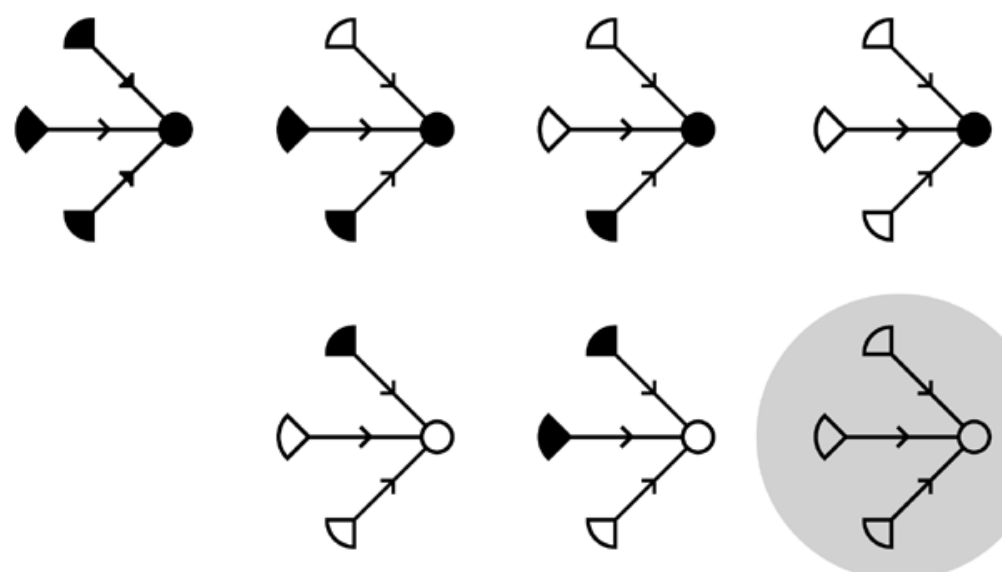

\section{Various derivations from an open design solution}
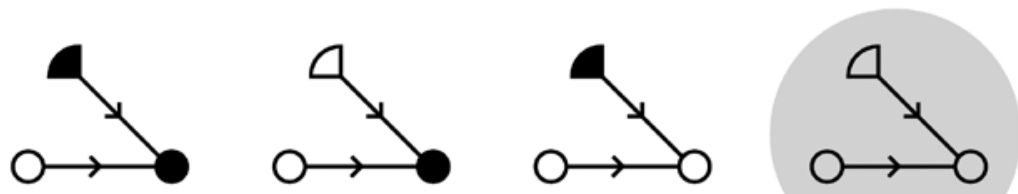

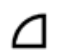

open design contribution from single contributor

$\begin{array}{ll}\text { design } & \text { open design } \\ \text { contribution } & \text { solution } \\ \text { from single } & \\ \text { contributor } & \end{array}$

design solution completely open design project / process

\section{Figure 1}

Visualizing open and non-open aspects of design processes. 
paying for internet access when downloading open designs online. Mari's work can be seen as an example of democratizing access to the work of designers, in that he considered accessibility, tools and materials that are available to the average person and that the products were within their capabilities to construct.

In 2010, a group of London-based designers working together under the name Ten exhibited a collection of works called Ten Plan at $100 \%$ Design. All of the projects were designed explicitly to be open, useful and reproducible (Jackson, 2010). Their work can be seen as part of a growing trend of professional designers who see the potential of not only freely distributing their intellectual property at no cost, but of creating works specifically geared for dissemination to non-professionals.

Where Mari's work and the work exhibited for Ten Plan was a brief foray into open design, Berlin-based Israeli designer, Ronan Kadushin, has put open design at the centre of his practice. His work explores the synergy between the Web's distribution capabilities, and accessible, flexible digital fabrication (CNC production to be exact) to encourage creative development of ideas from designers by consumers. In a recent interview he describes open design in these terms: 'A design is basically a piece of information that is on the network, which can be downloaded, changed, produced, copied and so on' (Kadushin, 2012).

However, his open design work is mindful of what it needs to be if it is to be open, in that the data to replicate his designs are freely available and the tools used to produce it are relatively accessible. Most of the work is cut from sheet steel, requiring anyone who wants to utilize his designs to have access to speciality fabricators who use digitally driven cutting technology, something that is relatively accessible in most industrially advanced metropolitan areas. With the rise of Fab Labs by MIT's Center for Bits and Atoms and open fabrication spaces, this type of digitally driven fabrication on demand may well become even more commonplace and publicly facing (Gershenfeld, 2005).

In summary, the design work of Mari, Ten and Kadushin can be defined as open design solutions resulting from a single designer's contribution, as can be seen in Figure 2. Their work can be used as starting points for others to derive from, allowing others to modify the design information for their own ends. However, if the modified designs are not shared openly, these subsequently cannot be considered open design solutions themselves but something derived from them.

\section{Co-designed Cars}

Involving people in a project, in informing and providing input to the design process from the start is much more challenging than simply distributing the design information once it has been created. For this type of design openness tools and systems are needed to facilitate 


\section{Figure 2}

Visualizing Mari and Kadushin's work using the icons.

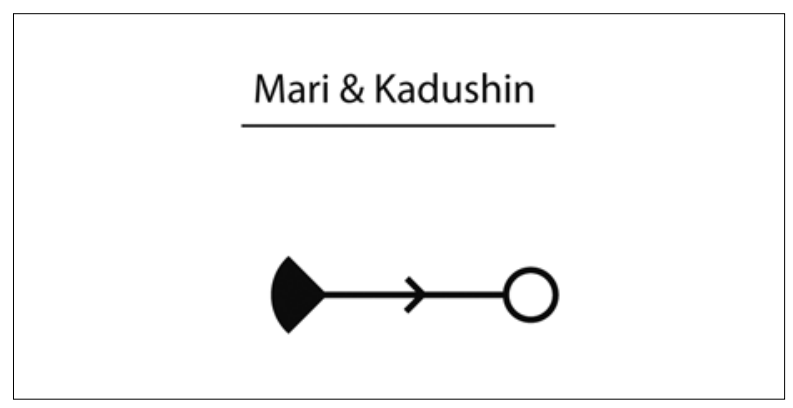

and encourage collaboration as well as manage the data gathered. It can be seen in the examples below that the internet is providing the necessary tools to enable this activity.

In 2009, the car manufacturer Fiat launched a co-design platform to crowdsource and develop concepts to imagine the car of the future. Between August 2009 and October 2010, over two million people in 160 countries visited the site and more than 17,000 ideas were submitted to the Fiat Mio website (Fiat, 2013). A team of professional designers and marketers at the Fiat Style Centre in Brazil then utilized the site to interact with people via chat rooms, gaining an understanding from their insights, desires, needs and criticisms.

Contributors to the project were able to make points, give ideas and comment on the contributions of others. Anyone, as long as they were motivated to do so, could make a contribution void of the need to know or use any design tools to participate. It fell to the design team at Fiat to interpret the wealth of content generated and use their expertise to develop concepts and build a series of prototypes that could then be shared with the community for further feedback.

No financial or material incentives were offered for participation; however, participants were rated in terms of the number of points, ideas and comments they had made, which created a hierarchy whereby people could earn kudos from their rank within the community. All content that was contributed is openly published on the Fiat Mio website, but the work generated by Fiat does not appear as open content on the website, so it can be judged that this project allows for open contributions as text but no usable design information is published by openly Fiat. The information released would not enable a person or company to make a facsimile of the Mio; there are no schematics or a bill of materials published to enable fabrication by others. However, the conversation surrounding the ideation and feedback process coupled with the specifications of the $3^{\text {rd }}$-generation concept car (FCC III) would enable others to draw rich conclusions and gain insights into what people want from a future car.

In contrast to the Fiat Mio project, the American car company Local Motors (www.localmotors.com) has, with the aid of online 
collaborators, developed the Rally Fighter (Anonymous, 2013a). The Rally Fighter is an on- and off-road sports car that customers are able to build at the Local Motors Micro Factory with professional assistance. Many similarities can be drawn between Fiat's approach and that of Local Motors, but where they differ is the degree to which the Arizona-based company has opened up its entire process and created a platform for users of the site to contribute and collaborate on designs.

The Rally Fighter can be seen as a truly open project; CAD models of all parts fabricated by Local Motors are available to download in .sld, the file format for Dassault systems Solidworks, which allows for a high degree of editability using professional industry standard software. A comprehensive parts list can also be viewed online and downloaded that names, itemizes and lists the suppliers of all components needed. Build manuals can be accessed and printed from a wiki-style section of their website, thus allowing for user improvement to documentation.

The Forge is Local Motors' co-creation social networking and design platform, which allows projects, completions and user profiles to be viewed and interacted with. Each of the over 17,000 users has an individual page that shows a detailed profile, projects they have worked on, competitions entered and prizes gained, the opportunity to follow the work of others and have followers themselves, and a show real of their work.

Through competitions run on the Forge platform, Local Motors has partnered with brands such as BMW in the Urban Driving Experience Challenge and Domino's Pizza to design the Ultimate Delivery Vehicle. Whereas in the Mio project all contributions were in the form of text, the Forge allows for people to contribute in a much broader and creative way, enabling participants' opportunities to be rewarded for their input through competitions, and a platform through which they can demonstrate their abilities.

In the Rally Fighter, a car that was co-designed with an online community and is now published in its entirety online, it is possible to see an extremely open design process. In addition to that, the Forge as a design platform goes far beyond that of the Mio project in creating an asset of value to brand partners, and most of all contributors.

There is a business element to these two vehicle-based open design platforms that leverage the power and potential of the crowd. In both cases openness forms a strategic part of their business model; at the stages at which contribution is garnered, the types and flexibility of contributions and the open publication of both design contributions and solutions, is where they differ.

In summary, as illustrated in Figure 3, the Fiat Mio project is an open innovation project that allows for text-based open design contributions. In contrast the development of the Rally Fighter can be seen as an open design project as it allowed for open contributions and published the final design openly. The Forge is more complex as 


\section{Figure 3}

Visualizing an overtly simplified view of the Fiat Mio project and the Rally Fighter using the icons.

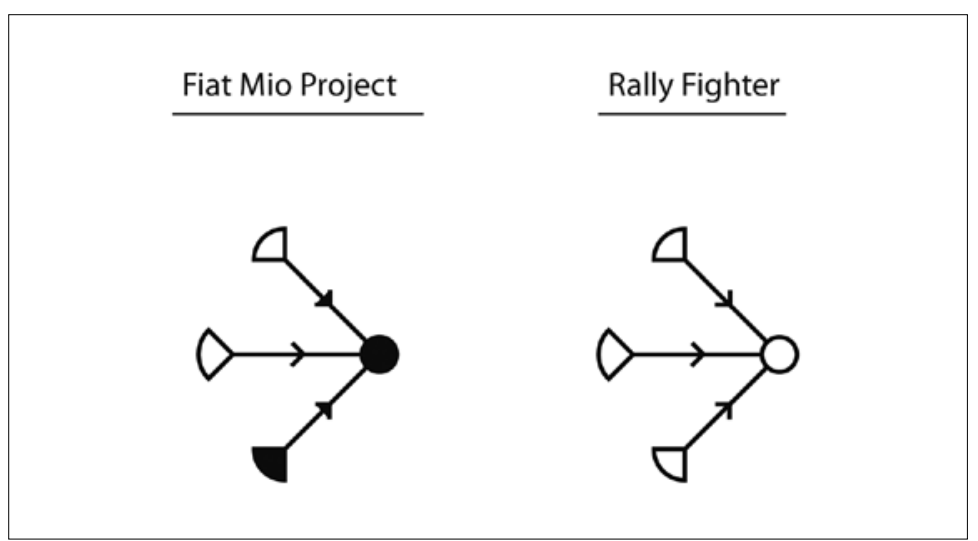

it allows for open design contributions and open design solutions in a wide array of formats for co-design, open source innovation and open design projects.

\section{Openness with an Agenda}

The Global Village Construction Set by Open Source Ecology (OSE) (Anonymous, 2013b) (www.opensourceecology.org) and Defense Distributed (Wilson, 2013) (www.defensedistributed.com) are projects that hope to leverage the potential of the open sharing and creation of design content for a sociopolitical agenda. They have both created a Web-based platform to share design and instructional knowledge as well as allowing for input from others. They both use wikis to allow their users to add, modify or delete content via a Web browser usually using a simplified markup language or a rich-text editor. Wikis are powered by wiki software (Anonymous, 2013c). Due to the nature of the founding principles, they set the frame for the type of discussion and content they want to attract. In a similar manner to that of Local Motors and the Mio project, these two projects can be seen to be converging on a solution or set of solutions to fit a specific agenda.

OSE aims to make closed-loop manufacturing a reality; it is a network of farmers, engineers and hundreds of online volunteers that have been creating the Global Village Construction Set (GVCS). The 'GVCS is a modular DIY, low-cost, high performance technological platform that allows for the easy fabrication of the 50 different industrial machines that it takes to build a small sustainable civilisation with modern comforts' (Anonymous, 2013b).

Contribution to the wiki and forum is predominantly through text format with a high degree of topic segmentation, and in order to contribute to both it is necessary to sign up. All the information to fabricate each part of the construction set is contained in the project wiki, including a complete set of fabrication drawings, CAD files and bill of materials. It is also used as a repository for detailed 
descriptions of various aspects of the project, as well as a glossary to explain terminology, and links to similar projects.

For others to contribute, beyond posting on the forum or adding content to the wiki, OSE specifically asks contributors who have particular expertise and certain skill sets in areas such as prototyping and fabrication, project management, mentorship, design, Web development and documentary production to contact them directly. The forum does act as a space for co-design and development, where visual design contributions in the form of CAD files or images can be posted, although currently the display of the contributions is very small and their success might be hindered by this low visibility. The onsite wiki is extensive and acts as a tool for dissemination and classification.

Defense Distributed is a contentious project that has developed a fully 3D-printable gun, the 'Liberator' pistol or 'Wiki Weapon', the design of which is in theory open and free to download. The result is an easily distributed and replicable design. The project's aim is to change the way people think about gun control and consumption in light of the possibilities of 3D printing. The US State Department deemed the files fell under the control of the International Traffic in Arms Regulations and so demanded they be removed from the group's website defcad.org days after they were released. Defense Distributed estimate that the Liberator files were downloaded 100,000 times before they were taken offline (Greenberg, 2013). Now that the files have been downloaded their censorship by any agency or state is near impossible, the Pirate Bay (www.thepiratebay.se.net) an online file-sharing site, is hosting the files at the time of writing.

Similar to the OSE project, Defense Distributed used a wiki to invite and disseminate design and other contributions, with their aim being the establishment of a 'printable gunsmithing commons' (www.defensedistributed.com/faqs/why-guns). The content in the project appeared to be the work of a few people who set up the site, most notably Cody Wilson. It seemed open for contributions, but as with the OSE project, those contributing did not have online profiles where their input was recognized; so it was difficult to see who is doing what, and if in fact there was any input coming from an online community.

In summary, OSE and Defense Distributed both allow for and document open design contributions and publish design solutions openly. Solutions also form the basis of further developments tied to the aims of the project as can be seen in Figure 4, where the aim is to create a particular outcome or outcomes.

\section{Open Design Systems}

Where the previous examples of online platforms either focused on goals of manifestos or product types, the next two projects are based around systems that guide users in their application. These 


\section{Figure 4}

Visualizing an overtly simplified view of the WikiHouse and OpenStructures projects using the icons.

\section{Wiki House and Open Structures}

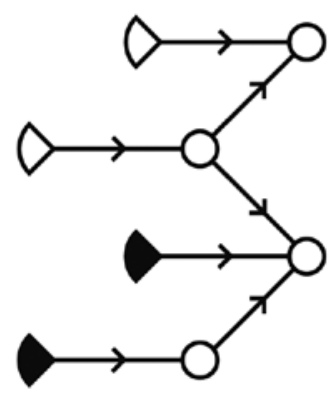

projects effectively create repositories of parts based around commonalities that could grow into universal open design and construction systems.

Started in 2011, The WikiHouse project (www.wikihouse.cc) is an open community project that aims to make it possible for anyone to design a piece of architecture for someone else (Parvin, 2013). It is a construction that allows for the design, download and CNC milling of houses and components, which can be assembled with minimal formal skill or training. Designs are based around the use of 1220 $\mathrm{mm} \times 2440 \mathrm{~mm}$ sheets of $18 \mathrm{~mm}$ plywood, being appropriate both due to its structural qualities as well as accessibility in terms of its relative ubiquity and affordability globally.

The website contains a comprehensive guide for designers and a list of modelling standards to help designers create or adapt projects effectively. The site also contains links to free CAD software (Google SketchUp), as well as a specially created plug-in for SketchUp that automatically prepares thumbnails of a model, generates 2D cutting templates of all the elements in the model and then uploads these to the WikiHouse website. To access CAD data and cutting templates of previously designed buildings there is a visual menu that guides the user to each project.

The tools used to cut components for the house include CNC milling, laser cutting or water-jet cutting and effectively cut 2D parts for assembly. The design files used to create the full scale parts can also be used to make scaled down prototypes from card or thin plywood that are then constructed in almost the same method as the full-scale house. As the design files are freely accessible this type of prototyping helps people, especially those new to construction, to understand potential difficulties in constructing someone else's design or imagine how to create their own designs. 
The OpenStructures (OS) project (www.openstructures.net) explores the possibility of a modular construction model where everyone designs for everyone on the basis of one shared $4 \mathrm{~cm} \times$ $4 \mathrm{~cm}$ geometric grid (Lommee, 2012). OS is a kind of collaborative Meccano to which anybody can contribute parts, components and structures. The project is not focused on a particular outcome; instead, it is very open ended, allowing for the creation of products, interiors and architecture. It is based on a four-tier system of single material parts, components comprised of multiple parts, structures made up of both components and parts and at the top tier superstructures, which are assemblies of structures and are predominantly seen as buildings. All elements - either through their dimensions, their assembly points or their diameter - must relate to the OpenStructures grid system to ensure compatibility. All elements must be able to be disassembled down to a single material part in order to allow for reuse in other OS components (Lommee, 2013).

The process for designing with the OS system is documented in great detail and is geared to the novice user. Great lengths, both visually and in the language used, have been taken to allow access to, and understanding of, their design methodology and system. Upon signing up, contributors can upload their own design content and documentation, which is then added to the OS database. To look for other projects the elements database has fairly comprehensive search options, which allows for filtering by level of element, material, designer and copyright attribution. In theory it is possible to upload and edit at all levels, select parts you want to edit or use, get access to CAD drawings, and information on who, when and where the element was created, as well as its relationship to other elements at other levels. It is also possible to contact the designer directly to ask questions. In practice only some elements offer the ability to download CAD data, or the option to contact the creator, effectively restricting the use of that particular design. Some parts that have CAD files available to download give no indication of the manufacturing process by which they are made; the only course of action for those wanting to use the file is to contact the creator directly. Some information regarding projects is found on the site blog and inferences can be made regarding processes used. So far 22 designers are listed as contributors with some of the submissions missing vital pieces of information required to make them; it is only possible to determine the extent to which the final design output is open on a case-by-case basis.

Both the WikiHouse and the OpenStructures project have visual menu systems for selecting parts. They both have comprehensive guides for understanding the design principles and use standardization as a means to enable users, by creating a set of tools or rules to apply. The restrictions or guidelines are created to enable users, rather than set the terms of what is to be developed. 


\section{Figure 5}

Visualizing an overtly simplified view of the Open Source Ecology and Defense Distributed projects using the icons.

\section{Open Source Ecology \& Defence Distributed}

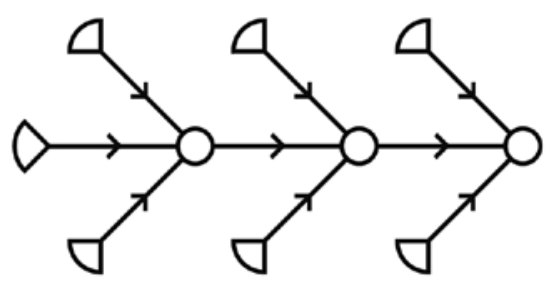

In summary, as illustrated in Figure 5, the WikiHouse and OpenStructures projects publish open design solutions as well as allowing for open design contributions. Designs are shared and utilized in the creation of multiple open design solutions rather than attempting to converge on one or a given number of outcomes.

\section{Open Sharing and Design Platforms}

Open sharing and design platforms can be seen as a kind of library of things. They do not need to be specific in what is shared nor, tied to any overarching theme like WikiHouse, nor sociopolitical agenda, such as Open Source Ecology, or based on a modular or constructional system such as OpenStructures. Two prominent but differing examples are Thingiverse (Makerbot Industries, 2013) www.thingiverse.com and Instructables www.instructables.com (Autodesk, 2013).

Thingiverse is a Web platform that hosts and freely distributes information and, importantly, CAD data to allow people to replicate and derive from other people's design projects. This is done mainly in the form of .stl files (Standard Tessellation Language), as they are currently the file format of choice for use with 3D printers; however, they are simply a representation of points in three-dimensional space and so are void of the information that shaped them. Some users share .sld files (Solidworks) or other file formats that, with the right software, anyone can see and can adapt the 'design tree' (the process by which the object was created) and so make derivatives from them.

Anything from mobile phone cases, replacement parts, mechanisms, toys, furniture fixings and a multitude of experiments have been uploaded and shared. The majority of objects added to the Thingiverse platform, are designed and produced using digital technologies. At the time of writing this paper, the database holds 18,566 things that overwhelmingly have been contributed by people not affiliated to the team running the site. 
Contributors to the site can have their own profile page to show the projects they have uploaded, as well as a list of physical tools they have at their disposal offline. Searching for projects is possible by theme, tools used, contributor and date uploaded. Projects can be searched by meta-tags that users attach to each project as a means to describe it. Within the site there is a forum for discussion, and users can also make comments on the projects of others allowing for more information to be gained; all this content is open for others to read.

Where Thingiverse is predominantly focused on sharing CAD data for direct digital manufacture, Instructables caters for all kinds of creative practice. As the name suggests many projects uploaded to the site carry detailed instructions for others to follow. For traditional craft and manufacturing technologies, as with other endeavours, instructions are the data needed to carry out making or doing something. Instructables caters to the open sharing of all do-it-yourself practice, and within that the sharing of open design solutions. As a platform it is not limited by or focused on the use of any making technology or creative endeavour; it encompasses how-to instructions on everything from gardening, cooking to furniture, electronics and even projection mapping on to buildings (datbates, 2013). The sharing of documentation as text, photo, video, and in almost any format is possible and, as with Thingiverse, CAD data can also be shared. Co-branded competitions are run on the site for which prizes are available; however, these are submitted by users as singular projects; it is not a co-creation platform with an open forum, like Local Motors or Fiat Mio. Comment can be made by anyone on any project that is open for all to read, and there is a culture of asking for full disclosure of documentation where the creator has omitted details or files, to allow for as many people as possible to access and use what is being shared.

In summary, Thingiverse and Instructables can be seen as platforms that enable users to share open design solutions; where people can give feedback to the original creator, to openly contribute their own ideas as well as edit the work themselves for subsequent use or open publication.

\section{Discussion}

The internet is the major enabler of openness in a multitude of fields, by allowing for information to be distributed globally for the cost of connection. In design this makes it possible to share ideas regarding objects, systems or ideologies with people who want to both use those ideas and contribute to them. For those who can see the value of openness in design, it is possible to leverage the connectedness of the internet to achieve ends that previously would be near impossible. This can be seen in all the project examples in one way or another. 
It is important to state that openness is neither seen as positive or negative in this paper, simply a descriptor. Therefore, using the terms stated in the paper do not connote quality or benefit in the design. Where descriptions are given of designs and documentation is created specifically for the layperson to follow or make themselves, this must not be read as a prerequisite to determine the openness of a design solution. The examples of work by Mari, Ten and Kadushin give an indication of an important aspect in the creation and usefulness of open designs: if the intention is for non-professionals to follow the plans then it is prudent to design them in a way that is accessible to them, whether that is the cost of materials, access to tools and machinery, the making or design skills needed to achieve a desired outcome. An open design, much the same as any design, needs to take the user into account, if it is going to be used. This too is an important note for co-design projects that garner open design contributions, in that the process of designing needs to be relevant to the aims of the projects. What this means for setting up open design projects or creating open design solutions in the future, is that accessibility and appropriateness of any open feature would need to be judged by the intentions of the designer or commissioner.

For any project that wants to enable people to contribute to a design process openly and collaboratively, a range of tools for both expressing and discussing ideas need to be made available and within people's ability to use effectively. Alongside this, resources need to be available that aid both novice and professional designers in areas such as material selection, machine capabilities, design for disassembly and other factors that are inherently important in the design of physical things. Where people's ideas and designs are in effect given away for free, issues of intellectual property, attribution and legality (specifically in the case of Defense Distributed) will need to be, and are being, addressed. Evidence of this is seen in the use of Creative Commons licences (Anonymous 2013d) and the recent enforced withdrawal of 3D-printable firearm parts by the US Department of Defense Trade Controls from the www.defcad.org, a file-sharing platform set up by Defense Distributed (Anonymous 2013e).

\section{Conclusion}

Through defining various aspects of collaborative design and open design, specifically in relation to open design contributions and open design solutions, this paper intends to give the subject of open design some clarity of language that can be used in future discussions. This terminology can aid in describing projects that are the result of one designer working alone on designs that they distribute freely without restriction and to online collaborative projects that result in a prototype design where the solution was not openly distributed as well as open-ended projects where the intention is the ongoing creation of a repository of interconnecting object designs. 
Each brief summary encapsulates complex notions. To state that the Fiat Mio project is an open innovation project that allows for textbased open design contributions is to recognize that Fiat sought out people's ideas and opinions in the form of the written word, which were openly published, but the resulting design outcome was not made available openly for unrestricted use. To state that Enzo Mari's Autoprogettazione project does not classify him as an open designer in that instance is not disingenuous but merely states that he was not involved in an open design process where open design contributions led to an open design solution. We can say of Mari that he is a designer of open design solutions. These statements do not make judgements as to the quality of the designs, or whether these acts can be considered good or bad.

The authors acknowledge the illustrations in the figures when applied to the project examples overly simplify each case. They are intended as a means to identify key attributes of projects where contributions or design solutions are openly distributed. Due to the complex nature and relative ambiguity of the non-open aspects of certain projects this method has shortcomings as a pure analytical tool; however, the illustrations could be used to map out potential projects or as a discursive mechanism to compare examples as has been used in this paper.

All this shows is that it is possible to capture and compare quite complex projects and processes with relative clarity. It is the intention of this work to enable others to define projects with more clarity and uniformity - specifically in identifying open design solutions, open design contributions, open design processes, open designing, open design projects, co-design, co-creation, open innovation and open source innovation - whether that is in the process of defining the scope and intention of a future project, or in describing the work of others.

\section{References}

Anonymous (2013a). Local Motors: Empowering a World of Auto Makers. Available at: http://www.localmotors.com/ [accessed 1 February 2013].

Anonymous (2013b). Open Source Construction Set. Available at: www.wikihouse.cc [accessed 1 February 2013].

Anonymous (2013c). Wikipedia: The Free Encyclopedia. Available at: http://en.wikipedia.org/wiki/Wiki [accessed 1 February 2013].

Anonymous (2013d). Creative Commons Licenses. Available at: http://creativecommons.org [accessed 1 February 2013].

Anonymous (2013e). 3D Printed Firearms Removal by USDTC. Available at: http://defcad.org [accessed 10 April 2013].

Autodesk (2013). Instructables - Make, How to and DIY. Available at: http://www.instructables.com/ [accessed 1 February 2013).

Avital, M. (2011). 'The generative bedrock of open design'. In van Abel, B., Evers, L., Klaassen, R. and Troxler, P. (eds), Open 
Design Now: Why Design Cannot Remain Exclusive. Amsterdam: Premsela and Waag Society, pp. 48-58.

Chesbrough, H. W. (2003). Open Innovation: The New Imperative for Creating and Profiting from Technology, Boston, MA: Harvard Business Press.

Chesbrough, H. (2006). Open Business Models: How to Thrive in the New Innovation Landscape. Boston, MA: Harvard Business School Press.

datbates (2013). Projection Mapping with 3D Tracing. Available at: www.instructables.com/id/Projection-Mapping-with-3D-Tracing [accessed 3 April 2013].

Fiat (2013). Fiat Mio: The World's First Crowdsourced Car. Available at: www.fiatmio.cc/en [accessed 2 May 2013].

Gershenfeld, N.A. (2005). Fab: The Coming Revolution on Your Desktop: From Personal Computers to Personal Fabrication, $1^{\text {st }}$ edn. New York: Basic Books.

Greenberg, A. (2013). ‘3D-Printed gun's blueprints downloaded 100,000 times in Two days (with some help from Kim Dotcom)'. Available at: http://www.forbes.com/sites/ andygreenberg/2013/05/08/3d-printed-guns-blueprintsdownloaded-100000-times-in-two-days-with-some-help-fromkim-dotcom/ [accessed 29 May 2014].

Heskett, J. (2005). Design: A Very Short Introduction. Oxford: Oxford University Press.

Jackson, C. (2010). 'We talk about design and sustainability'. TEN. blog. Available at: www.tenproject.wordpress.com [accessed 2 May 2013].

Kadushin, R. (2012). Open Design Manifesto. Available at: http:// www.ronen-kadushin.com/index.php/open-design/) [accessed 10 February 2013].

Lommee, T. (2012). Open Structures. Available at: http://www. openstructures.net/ [accessed 12 December 2012].

Lommee, T. (2013). Common Design Guidelines. Available at: www.openstructures.net/pages/9\#deel1b [accessed 2 May 2013].

Makerbot Industries (2013). Thingiverse Digital Design for Physical Objects. Available at: http://www.thingiverse.com/ [accessed 1 February 2013].

Mari, E. (2002). Autoprogettazione? $1^{\text {st }}$ edn. Mantova: Corraini.

Menichinelli, Massimo (2011). Open P2P Design Toolkit, How to Co-design an Open Collaborative Process. Aalto University: openp2pdesign.

Menichinelli, Massimo (2013). Working on the Open Design Definition, February 26. Available at: http://design.okfn.org/2013/02/26/ working-on-the-open-design-definition/ [accessed 2 March 2013].

Moody, G. (2002). Rebel Code: Linux and the Open Source Revolution. Cambridge, MA: Perseus Books Group. 
Muthukumaraswamy, K. (2010). 'When the media meet crowds of wisdom: How journalists are tapping into audience expertise and manpower for the processes of newsgathering'. Journalism Practice, 4(1): 48-65.

Open Knowledge Foundation (2013). Open Definition. Available at: http://opendefinition.org/ [accessed 2 May 2013].

Open Source Initiative (2012). The Open Source Definition. Available at: http://opensource.org/docs/osd [accessed 2 May 2013].

Parvin, A. (2013). WikiHouse: An Open Source Construction Set. Available at: http://www.wikihouse.cc/ [accessed 2 May 2013].

Raasch, C., Herstatt, C. and Balka, K. (2009). 'On the open design of tangible goods'. R\&D Management, 39(4): 382-393.

Richter, W. and Cassarino, I. (2008). 'Swarm creativity - The legal and organizational challenges of Open Content Film production'. In Birkbeck College (ed.), Swarm Creativity - The Legal and Organizational Challenges of Open Content Film Production. DIME conference on The Creative Industries and Intellectual Property, Birkbeck College, London, 22-23 May.

Sanders, E. B. and Stappers, P. J. (2008). 'Co-creation and the new landscapes of design'. Co-design, 4(1): 5-18.

Smith, Z. (2008). 'Objects as software: The coming revolution'. In Objects as Software: The Coming Revolution, 25 $5^{\text {th }}$ Chaos Communication Congress, Berlin.

Vallance, R., Kiani, S. and Nayfeh, S. (2001). 'Open design of manufacturing equipment'. In Proceedings of the CHIRP $1^{\text {st }}$ International Conference on Agile, Reconfigurable Manufacturing. Cambridge, MA: MIT, pp. 33-43.

van Abel, B. (2011). 'Cases'. In van Abel, B., Evers, L., Klaassen, R. and Troxler, P. (eds), Open Design Now: Why Design Cannot Remain Exclusive. Amsterdam: Premsela and Waag Society, pp. 214-239.

Wales, J. (2005). 'Wikipedia in the free culture revolution'. Conference on Object Oriented Programming Systems Languages and Applications: Companion to the 20th Annual ACM SIGPLAN Conference on Object-oriented Programming, Systems, Languages, and Applications, p. 5. San Diego, CA, 16-20 October 2005.

Wilson, C. (2013). Wiki Weapon 3Dprintable Gun. Available at: www. defensedistributed.com [accessed 2 May 2013].

\section{Biographies}

James Tooze is an independent designer and researcher at The Royal College of Art. His research with Dr Sharon Baurley focuses on three interwoven areas of open design, open fabrication and digital manufacturing. Conducted with Horizon, a Digital Economy Research Hub, for the Artefact Cafe Project. Prior to studying at the RCA he worked for a number of years as furniture designer and maker and this experience, coupled with a fascination with digital 
manufacturing and high value of craftsmanship and hands-on making, shapes his work.

Robert Phillips is a product designer and a PhD candidate at the Royal College of Art, investigating the partnership between open design and citizen science. He is interested in the new opportunities digital fabrication can bring to the design process and fascinated by people-orientated solutions. His industry background has included: human-computer interaction, ethnography, material development, design for manufacture, technology applications, concept generation and territory-exploring workshops.

Dr Sharon Baurley is Head of Design Products at the Royal College of Art. She joined the RCA in 2013, and was formerly at Central Saint Martins College of Art and Design (UAL). Her research focuses on 'open design' digital tools and social technologies so that consumers can have design conversations with brands, funded by the RCUK Digital Economy programme. She is currently working with Horizon, a Digital Economy Research Hub.

Edwin Foote is a graduate of Industrial Design at Brunel University and researcher at the Royal College of Art. His work for the RCUK Digital Economy funded project: 'User Innovation Communities: Digital Tools for Cultural Production' investigates tools and techniques that might enable people create and share their ideas and thoughts in design conversations with a retail brands.

Dr Sarah Silve is a lecturer in product design at Brunel University. Her background is in silversmithing, jewellery, and laser forming for crafts applications. She is interested in step changes of technologies and processes for creative outputs that evolve practice and design; current projects include CNC paste deposition modelling. Her research encompasses new materials, laser material processing, rapid prototyping, user interfaces and open design.

Dr Paul Smith is a Research Fellow at Glasgow School of Art. Trained as a Product Designer, he has a PhD researching generative design for 3D printing. His research looks at future application of digital fabrication technology, participatory design and design thinking. He has lectured on 3D print technologies and was a guest lecturer at the Manufacturing Institute, focusing on advanced CAD and 3D print technology.

\section{Addresses for Correspondence}

James Tooze, Royal College of Art, Kensington Gore, London SW7 2EU, UK.

Tel: +44 2075904444

Email: info@jamestooze.com 
Dr Sharon Baurley, Royal College of Art, Kensington Gore, London SW7 2EU, UK.

Tel: +44 2075904444

Email: sharon.baurley@rca.ac.uk

Robert Phillips, Royal College of Art, Kensington Gore, London SW7 2EU, UK.

Tel: +44207590 4444

Email: info@rdphillips.co.uk

Dr Sarah Silve, Brunel University, Uxbridge Campus, Kingston Ln, Uxbridge, Middlesex UB8 3PH, UK

Tel: +44 1895274000

Email: sarah.silve@brunel.ac.uk

Edwin Foote, Royal College of Art, Kensington Gore, London SW7 2EU, UK.

Tel: +44207590 4444

Email: edwin.foote@rca.ac.uk

Dr Paul Smith, The Glasgow School of Art, 167 Renfrew St, Glasgow G3 $6 R Q$, UK.

Tel: +441413534500

Email: p.smith@gsa.ac.uk

\section{Acknowledgements}

This work is supported by The Research Councils UK Digital Economy Programme (EP/I032061/1), and Horizon Digital Economy Institute. 